\title{
Tips for Successful Artificial Insemination in Beef Cattle ${ }^{1}$
}

\section{Daniela Cortés-Beltrán and Angela Gonella²}

\section{Introduction}

Artificial insemination (AI) is an assisted reproductive technology used worldwide in which semen is deposited directly into the female's uterus. It is considered a tool that has the advantage of improving reproduction and genetic quality of livestock. This technique is frequently used in the industry to enhance certain characteristics for improved genetic selection in cattle.

Artificial insemination has significant benefits. These include the exchange of genetic material from high-genetic value sires at relatively low cost without the issue of animal transportation, reduced cost of bull maintenance, and reduction of venereal diseases in the farm (Fontes, Oosthuizen, and Cliff Lamb 2020; Noackes et al. 2001; Vishwanath 2003). The correct application of the technique is essential. Therefore, this publication is directed to beef producers, farmworkers, and Extension agents with the purpose of providing tips on how to perform successful artificial insemination in a beef cattle operation.

\section{The Artificial Insemination Kit}

The basic insemination kit should contain a stainless-steel AI gun, semen straw cutter or scissors, tweezers, thermometer, a thaw unit, and an AI box to store and keep all the materials clean and organized. The kit should also contain disposable supplies such as split plastic sheaths, sanitary covers, plastic palpation gloves, non-spermicidal lubricant, and paper towels (Figure 1). The artificial insemination kit must be stored in a dry, dust-free, and clean place. It is essential to always clean it before and after the AI procedure.

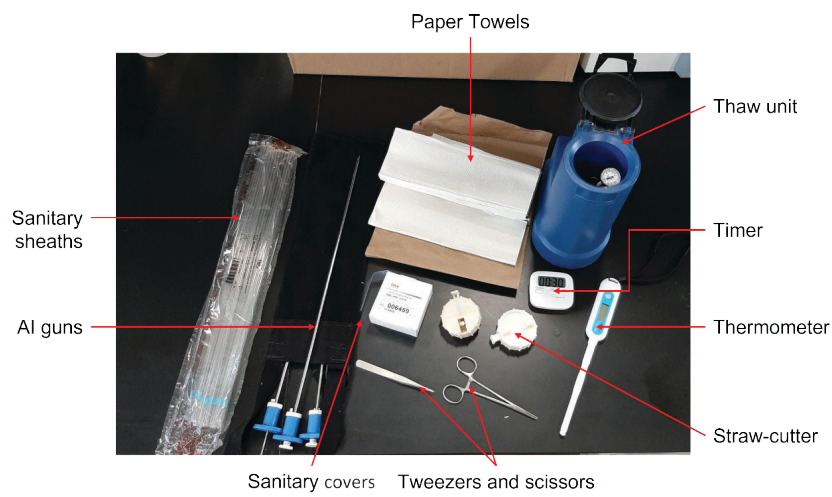

Figure 1. Basic artificial insemination kit.

Credits: Daniela Cortés-Beltrán and Angela Gonella

\section{Liquid Nitrogen Tank Management}

Periodically checking the nitrogen level in the tank is necessary to guarantee that the semen straws are always immersed in the liquid nitrogen. The liquid nitrogen has a temperature of $-196^{\circ} \mathrm{C} /-320^{\circ} \mathrm{F}$ (Noakes et al. 2001); always remember that nitrogen can cause injury to technicians (e.g., cold burns) if not handled carefully.

The tank should be kept in a clean, dry, and well-ventilated place due to the vapors produced by nitrogen when evaporating over time. Tank handling must be rigorous to preserve its vacuum-sealed system, given that the inner

1. This document is AN380, one of a series of the Department of Animal Sciences, UF/IFAS Extension. Original publication date December 2021. Visit the EDIS website at https://edis.ifas.ufl.edu for the currently supported version of this publication.

2. Daniela Cortés-Beltrán, DVM; and Angela Gonella, DVM, PhD, assistant professor, beef cattle reproduction; UF/IFAS North Florida Research and Education Center, Marianna, FL 32466.

The Institute of Food and Agricultural Sciences (IFAS) is an Equal Opportunity Institution authorized to provide research, educational information and other services

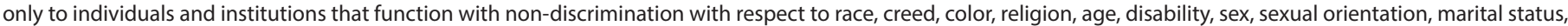

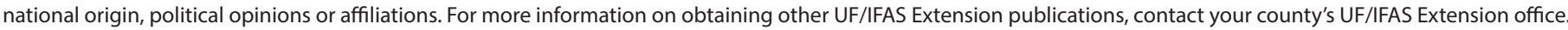
U.S. Department of Agriculture, UF/IFAS Extension Service, University of Florida, IFAS, Florida A \& M University Cooperative Extension Program, and Boards of County Commissioners Cooperating. Andra Johnson, dean for UF/IFAS Extension. 
chamber is suspended from the exterior by the neck (Figure 2 ). For this reason, it is always recommended to use the handles of the tank to move it and to use gentle movements. Additionally, the tank must be protected from corrosive and wet surfaces, so it is recommended to keep it elevated from the ground using cardboard or wooden pallets.

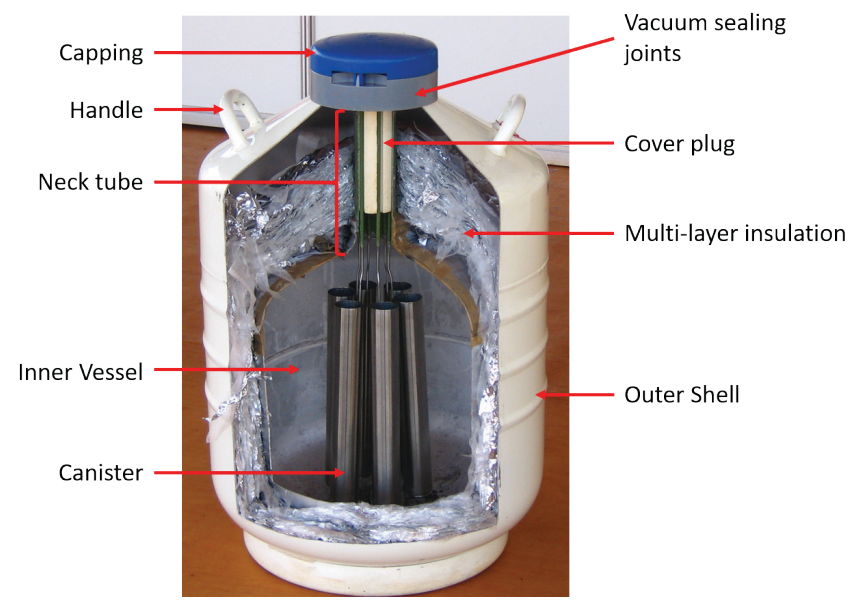

Figure 2. The inner structure of the liquid nitrogen storage tank. Credits: Original picture courtesy of Dr. Alejandro Ojeda

When handling is incorrectly performed, the first sign of loss of vacuum and quick liquid nitrogen evaporation is the accumulation of an icy frost layer around the neck. At this point, it is necessary to consider replacing the storage tank in order to preserve the quality of the stored semen. To facilitate location and handling of the tank, it is also recommended to have an updated list with complete information about the semen straws stored inside the tank.

\section{Semen Straw Handling}

It is crucial to properly handle semen straws to remove them from the liquid nitrogen tank. The technician must keep the canister, cane, and unused semen straws as close to the neck of the tank as possible for no longer than 5 to 8 seconds. Always minimize exposure to high temperatures, which promotes thermal damage (Figure 3A).

The removal of selected semen straws should be under the lower half of the neck of the storage tank because this is where the temperature is adequate, approximately $-120^{\circ} \mathrm{C}$ (Table 1). Keeping semen in the upper half of the neck for longer periods promotes cell damage by allowing the formation of ice crystals inside the sperm cells, as temperatures increase (i.e., $-80^{\circ} \mathrm{C}$ to $-100^{\circ} \mathrm{C}$ ) in 20 seconds (Hopper 2015).

To maintain semen quality, it is essential to decrease the time of exposure outside of the tank and to use efficient handling. It is required to handle the semen straws with tweezers instead of bare hands and fingers due to the possibility of semen thermal damage and injuries to the technician (Figure 3B).

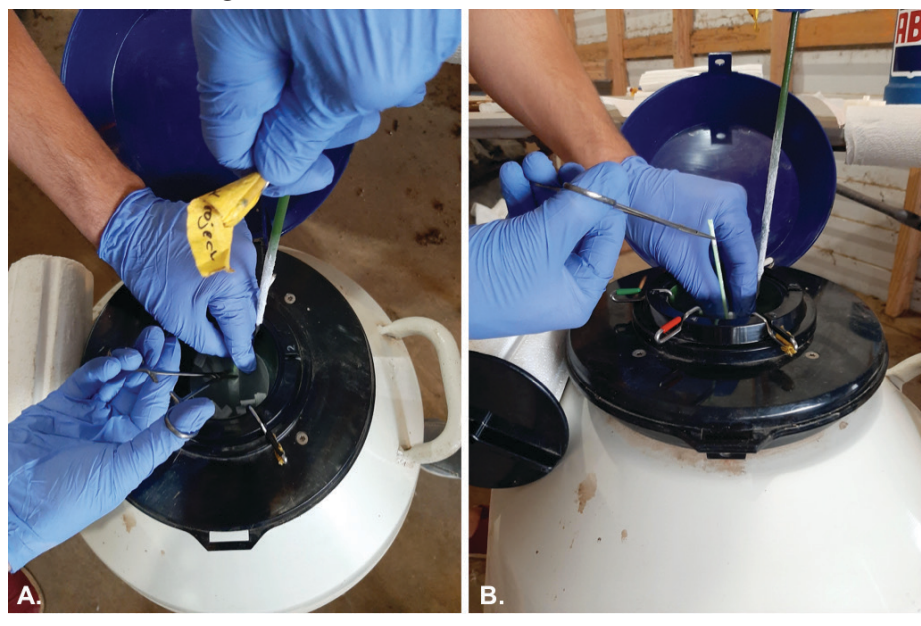

Figure 3. Proper semen handling technique. A. Semen straw removal near to the neck of the storage tank. B. Use of tweezers and gloves for semen quality and technician safety.

Credits: Daniela Cortés-Beltrán and Angela Gonella

Another critical point is the correct semen thawing procedure, which needs to be fast and under an adequate temperature. According to The National Association of Animal Breeders, thawing should be at $30^{\circ} \mathrm{C}-35^{\circ} \mathrm{C}\left(90^{\circ} \mathrm{F}-\right.$ $95^{\circ} \mathrm{F}$ ) for a minimum of 30 seconds. Slow thawing allows the recrystallization of ice in the sperm cell, causing cell membrane damage (Noakes et al. 2001). To thaw semen correctly, use a water bath or a wide-mouth thaw thermos with a thermometer for accurate temperature monitoring (Figure 4A). It is also a good idea to use a timer and allow 30 to 60 seconds before removing the semen straw from the thawing unit.

The semen should be deposited into the uterus within 15 minutes of thawing. Low conception rates have been associated with semen straws that were kept in the water or exposed to the environment for longer periods of time prior to placement into the uterus (Duponte 2007). Unless an experienced technician can breed multiple cows within this period, it is recommended to thaw one semen straw at a time.

After thawing, the semen straw should be:

- Dried with a paper towel to remove all water, which is highly spermicidal (Figure 4B)

- Protected from direct sunlight or UV light, which causes sperm cell damage

- Protected from drastic temperature changes, which cause thermal shock (leading to decreased motility) 
The AI gun should be warmed by rubbing it with a clean paper towel or placing it close to the body before inserting the semen straw to avoid thermal shock.

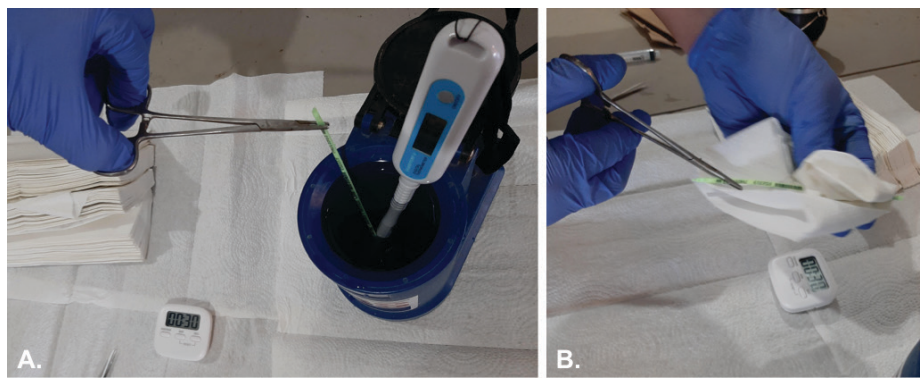

Figure 4. Semen thawing process. A. Water temperature monitoring with time control for proper thawing. B. Proper semen straw drying. Credits: Daniela Cortés-Beltrán and Angela Gonella

- Make sure the AI gun plunger is retracted to allow the insertion of the straw.

- Insert the straw by the cotton plug end.

- Do a perpendicular straight cut (not at an angle) in the sealed side of the semen straw, with a disinfected sharp straw cutter or scissors, to provide a good fit with the sanitary sheath.

- Slide and attach the split plastic sheath and lock it with the AI gun firmly, then check for a proper seal.

- Protect the sanitary sheath with a sanitary cover to prevent contact between the AI sheath and the animal's vagina in order to reduce the risk of bacterial contamination of the uterus.

- Keep the loaded insemination gun warm and protected from dirty surfaces until it is used.

\section{Proper Insemination Technique}

In cattle, the artificial insemination is performed using a recto-vaginal technique. The technician must be properly trained in this technique to guarantee good results. The proper handling of the reproductive tract and the ability to deposit the semen in the correct location inside the uterus are very important (Diskin and Kenny 2016).

\section{Before starting:}

- Check that all the supplies are available tobegin the AI process.

- The technician should wear clean protective clothing and must have trimmed nails.

- Pay close attention to the hygiene of the animal's perineal area to avoid contamination of the reproductive tract with pathogens.

Restrain the animal as carefully and gently as possible before insemination to minimize stress. The vulva region must be clean. Use paper towels to remove feces in order to prevent contamination and a possible infection in the uterus.

One disposable plastic palpation glove per animal with enough non-spermicidal lubricant should be used to gently enter into the anus and reach the rectum. Once the technician's hand is inside the rectum, the technician should make a fist and apply pressure on top of the vulva to open the vulval lips and then introduce the insemination gun tip into the vagina at a $30^{\circ}-40^{\circ}$ upward angle (Figure 5). This will avoid introduction of the gun in the urethral opening situated on the vaginal floor.

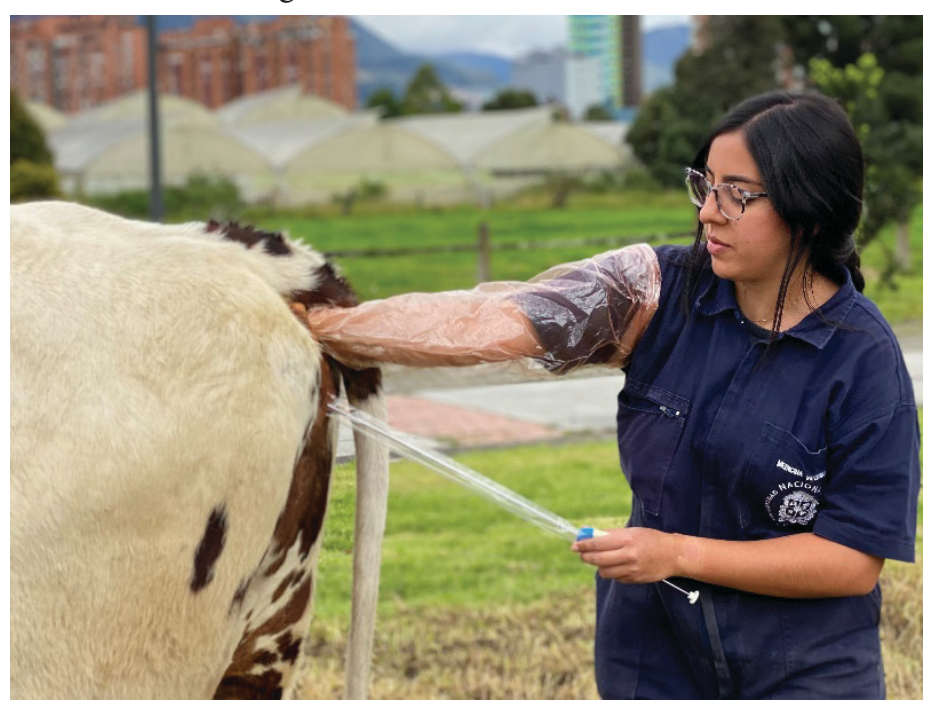

Figure 5. Introduction of the Al gun into the vagina at a $30^{\circ}-40^{\circ}$ upward angle.

Credits: Daniela Cortés-Beltrán and Angela Gonella

To perform the recto-vaginal AI method, it is essential to hold the cervix via the rectum; then, the insemination gun must be directed forward into the vagina until it reaches the external cervical os. It is necessary to dodge the fornix of the vagina and direct the insemination gun through the cervix by manipulation via the rectal wall.

Once the entrance of the cervix is reached, the sanitary cover must be ripped prior to entering the cervix. Usually, when the insemination gun reaches the cervix, there will be a unique gritty sensation. All cervical rings must be passed as the gun is driven forward. As a result, the animal will be inseminated in the uterus. Do not remove the AI gun right after the insemination; it can "pull back" some semen into the cervix by vacuum force, leading to a decrease in the chances of success of the AI technique. 


\section{Avoiding Trauma}

While driving the AI gun inside the animal's reproductive tract, from the vulva to the uterus, movements should be gentle. Inserting the AI gun too deep could cause damage to the endometrium, resulting in decreased fertility (Noakes et al. 2001).

Additionally, rough movements with the tip of the gun can cause vaginal, cervical, or uterine injuries, leading to reproductive failures and causing a poor prognosis for future fertility of the animal (Hopper 2015).

\section{Semen Placement}

Once the insemination gun crosses the cervix, the animal is going to be inseminated with a slow and gentle motion into the uterine body $1-2 \mathrm{~cm}$ from the entrance of the internal cervical os (Noakes et al. 2001). Proper placement of semen in the uterine body directly impacts the results of pregnancy per insemination. It has been reported that cervical insemination errors occur in about $20 \%$ of attempted uterine body deposits (Diskin and Kenny 2016). It is essential not to insert the tip of the AI gun into one of the uterine horns, due to the high risk of injuring the mucosa of the uterus' horn and depositing the semen in the contralateral uterine horn to the ovulation (Figure 6) (Noakes et al. 2001).

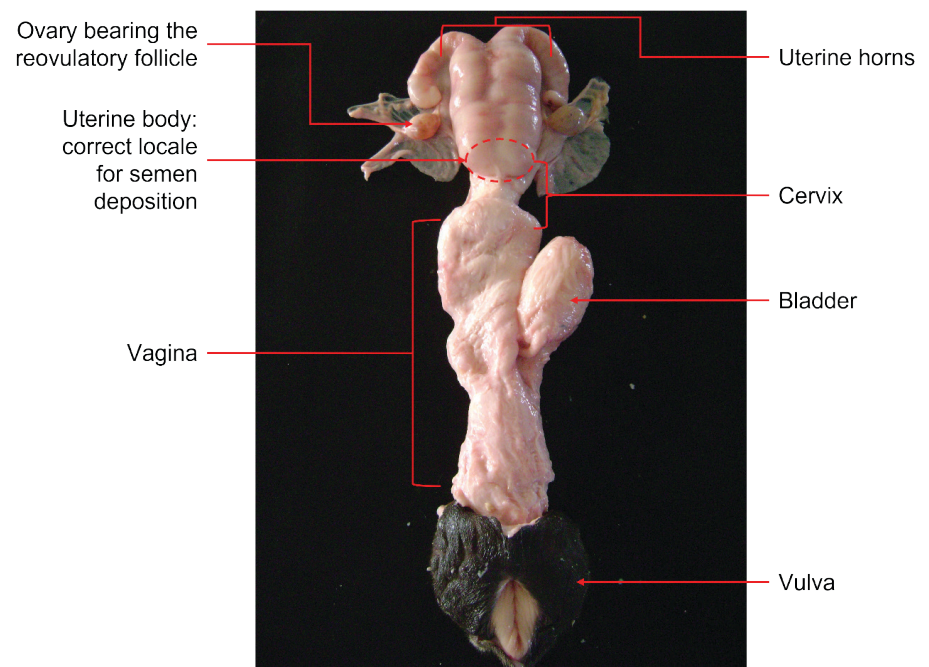

Figure 6. Reproductive tract of the cow.

Credits: Original photo courtesy of Dr. Cláudia Maria Bertan Membrive that it is common to combine artificial insemination with estrous and/or ovulation synchronization protocols that allow insemination of a large number of animals in a short period.

\section{References}

Diskin, M. G., and D. A. Kenny. 2016. "Managing the Reproductive Performance of Beef Cows." Theriogenology 86(1): 379-387. http://doi.org/10.1016/j. theriogenology.2016.04.052

Duponte, M. W. 2007. "Proper Semen Handling During an Artificial Insemination Program.” Livestock Management. https://www.ctahr.hawaii.edu/oc/freepubs/pdf/LM-16.pdf

Fontes, P. L. P., N. Oosthuizen, and G. Cliff Lamb. 2020. "Reproductive Management of Beef Cattle." Animal Agriculture:57-73. http://doi.org/10.1016/ b978-0-12-817052-6.00004-5

Hopper, R. M. 2015. "Artificial Insemination." In Bovine Reproduction, edited by W. Blackwell. 295-303.

Noakes, D. E., T. J. Parkinson, G. C. W. England, and G. Arthur. 2001. "Artificial Insemination." In Arthur's Veterinary Reproduction and Obstetrics, $8^{\text {th }}$ Edition, edited by W. B. Saunders. 751-778.

Saacke, R., J. Lineweaver, and E. Aalseth. 1997. "Procedures for Handling Frozen Semen." In Proceedings of the $12^{\text {th }}$ Conference on AI in Beef Cattle of the NAAB. 49.

Vishwanath, R. 2003. "Artificial Insemination: The State of the Art." Theriogenology 59(2): 571-584. http://doi. org/10.1016/S0093-691X(02)01241-4

\section{Summary}

Multiple variables are essential to the success of artificial insemination in cattle, and it is essential to pay attention to the details. Consult your local veterinarian or your local UF/IFAS Extension agent before implementing an artificial insemination program in your operation. Remember 
Table 1. Temperatures in the neck of the semen storage tank.

\begin{tabular}{|l|c|c|}
\hline \multicolumn{1}{|c|}{ Location } & Temperature $\left({ }^{\circ} \mathbf{C}\right)$ & Temperature $\left({ }^{\circ} \mathbf{F}\right)$ \\
\hline Top of neck & 2.2 to 12.2 & 36 to 54 \\
\hline $2.54 \mathrm{~cm}$ from top & -15 to -22.2 & 5 to -8 \\
\hline $5.08 \mathrm{~cm}$ from top & -40 to -46 & -40 to -51 \\
\hline $7.62 \mathrm{~cm}$ from top & -75 to -82 & -103 to -116 \\
\hline $10.16 \mathrm{~cm}$ from top & -100 to -120 & -148 to -184 \\
\hline $12.7 \mathrm{~cm}$ from top & -140 to -160 & -220 to -256 \\
\hline $15.24 \mathrm{~cm}$ from top & -180 to -192 & -292 to -313 \\
\hline
\end{tabular}

Source: Adapted from Saacke, R., J. Lineweaver, and E. Aalseth. 1997. "Procedures for Handling Frozen Semen." In Proceedings of the $12^{\text {th }}$ Conference on Al in Beef Cattle of the NAAB. 49. 